\title{
Performance of perforated FRP stub beams subject to static transverse actions
}

\author{
Alfred Kofi Gand ${ }^{a^{*}}$, Meer HM Mohammed ${ }^{a}$ and Slavi Jarrouj ${ }^{a}$
}

${ }^{a}$ School of Energy, Construction and Environment, Coventry University, Coventry, UK

\begin{tabular}{l}
\hline A R T I C L EI N F O \\
\hline Article history: \\
Received 12 August 2019 \\
Accepted 14 October 2019 \\
Available online \\
14 October 2019 \\
\hline Keywords: \\
Pultruded FRP \\
Web crippling \\
Cellular beam \\
Openings \\
Perforated beams
\end{tabular}

\begin{abstract}
A B S T R A C T
This paper presents an experimental programme designed to investigate the failure mode and ultimate capacity of pultruded glass fibre reinforced polymer (GFRP) cellular profiles subject to transverse loading. Presented in this study are the results of the characterisation of twenty six GFRP $152 \times 76 \times 6.4 \mathrm{~mm}$ I stub beams, $300 \mathrm{~mm}$ long. The beam specimens were categorised as plain for the control tests and those with circular or rectangular openings, centrally positioned. The specimens were subject to different loading configurations, noted as End Bearing with solid ground (EB), Interior Two Flange (ITF), Interior Bearing with solid base (IB) and End Two Flange (ETF). Results indicate a reduction in load-carrying capacity of the specimens with the opening when compared to the control specimens. The reduction was up to $20 \%$ for the specimens with circular openings and up to $25 \%$ for specimens with rectangular openings. The study revealed that loading configuration IB and ITF exhibit larger nonlinear behaviour and deformability than loading configurations EB and ETF. Various research has been conducted on its mechanical properties, connections, pultrusion techniques and web crippling behaviour of thin-walled GFRP section. Limited research can be found in the literature on the behaviour of pultruded GFRP beams with large perforation, subject to transverse static loadings.
\end{abstract}

(C) 2020 Growing Science Ltd. All rights reserved.

\section{Introduction}

During the early days of its development, cellular and castellated beams were mainly used for architectural purposes where the appearance of steel members with different shape web openings was considered aesthetically pleasing. Later, its application was common in shopping centres, parking buildings and most suspended floor structures. In addition, they represent a good resolution for curved roof applications (Erdal et al., 2011). The ability of cellular beams to incorporate low-cost manufacturing process accompanied by weight savings permits cellular beams to provide an economical method of constructing tapered members which are widely used in sports stadiums. In comparison, cellular beams are usually more economical and efficient than castellated beams because of their flexible geometry. Furthermore, cellular beams are approximately 40\% - 60\% deeper and stronger than the original member while reducing the total weight (Erdal et al., 2011). Pultruded fibre reinforced polymer (FRP), in general, have various applications in civil engineering industry, including strengthening of existing damaged structures, it can be used as reinforcing bars in concrete design, and it can also be used as main members such as beams or columns owning to the process of pultrusion which makes it easy to produce various

* Corresponding author.

E-mail addresses: a.gand@coventry.ac.uk (A. K. Gand)

(C) 2020 Growing Science Ltd. All rights reserved.

doi: $10.5267 /$ j.esm.2019.10.004 
shapes and sizes of FRP members (Hai et al., 2010). The existence of openings generally weakens the shear resistance of a beam while the flexural resistance is provided by the beam flanges. Local buckling of the tee section occurs as a result of shear transfer in the web which leads to failure mechanism caused by Vierendeel effect which is a common mode of failure in cellular beams. In rectangular sections the tee section is constant in the members along the opening length. Therefore, four critical sections (plastic hinges) form at corners of the rectangle. Moreover, in circular openings the critical section can be located using incremental approach (Durif and Bouchair, 2016). The advantage of adopting cellular beams as structural members are increasing the section modulus, and the flexural resistance of the member, economical and more aesthetically pleasing sections are produced by reducing weight and opening act as passage for services to go through the web which reduces floor depth (Zirakian \& Showkati, 2006). It is presumed that failure the mode of FRP and steel members are generally similar and due to the lack of research found in literature regarding pultruded GFRP cellular beams, it can be practical to take advantage of research on cellular steel members available in the literature. Panedpojaman et al., 2015, conducted an experimental study to provide an approach of calculating Vierendeel action on homogeneous steel beams with circular openings. In addition, most common failure modes were Vierendeel mechanism, and web crippling failure mode and studies conducted on castellated and other opening shapes showed that local buckling of the web-post failure mode is more common in closely spaced openings and slender profiles (Durif et al., 2013). A simplified method of analysing cellular beams in accordance with BS 5950 design guides were provided by (Pachpor et al., 2014) with a focus on the strength of Tee section and web-post main elements. Due to its lower young's modulus as compared to steel, these composite members are susceptible to buckling in the web due to concentrated loading hence the importance of web-crippling behaviour when designing pultruded GFRP members. Recent studies conducted by Chen and Wang (2015 a) emphasised this phenomenon and highlighted the typical failure mode in thin-walled GFRP structural elements as diagonal cracks $45^{\circ}$ at the web-flange junctions. Due to properties such as corrosion resistance, strength to weight ratio, ease of production and installation that adds to the reduction to assembly time and routing costs and their lightweight as compared to steel and concrete, GFRP is becoming a choice material in the civil engineering industry. The unavailability of a practical and simplified design guide is a critical setback to the use of FRP in the construction industry (Qiao et al., 2000).

Borowicz and Bank (2013) studied the web crippling effect of adding web reinforcement to pultruded fibre reinforced polymer beams under concentrated loading. A total of six flange beams and 5 wide flange beams were tested under IB loading configuration with the introduction of the following local reinforcement: (a) full depth web bearing stiffeners; (b) "doubler" plates attached to the web increasing the web thickness locally; (c) stiffening the web-flange joint of the upper flange longitudinally. The results show an increase of ultimate load capacity by $58.7 \%$ joint stiffeners, $52.8 \%$ bearing stiffener and $31.7 \%$ plate stiffeners as compared to the control specimens. It should be noted that only the web-flange joint stiffener prevented the formation of shear wedge failure in the upper flange joint. Moreover, for stiffening methods (a) and (b) an initial shear wedge failure had to occur before mobilising the strength of the stiffeners followed by excessive deformation and ductile behaviour. Bank et al. (1996) conducted a study on local compression flange buckling of pultruded GFRP beams. It was shown that buckling capacity of the beams was significantly influenced by the torsional stiffness of web-flange junction. Because of the orientation of the fibres, GFRP profiles generally show lower mechanical properties in the direction transverse to pultrusion, which makes these profiles very vulnerable to concentrated loads. A study lead by Borowicz and Bank $(2011,2013)$ presented an experimental method of understanding the web-crippling effect of GFRP pultruded small flange and wide flange I section with the different height ranging between $152.4 \mathrm{~mm}$ to $304.8 \mathrm{~mm}$ subjected to internal bearing loading configuration IB. It was concluded that the specimen's dominant failure mode was a shear failure at the web-flange junction with values of $20 \%$ to $46 \%$ of the in-plane shear of the material. A study on web crippling behaviour of composite FRP beams was conducted by Hai et al. (2010) using carbon FRP and glass FRP. In conclusion, it was found that the same failure modes occur at $45^{\circ}$ at the web-flange junction. 
Another experimental study conducted by Fernandes et al. (2015) examined the web crippling effect of pultruded GFRP I section beams under two loading configurations mainly the ITF and ETF with various bearing length $-15 \mathrm{~mm}, 50 \mathrm{~mm}$ and $100 \mathrm{~mm}$ ). The results show the dramatic effect of bearing length on the overall stiffness and load-carrying capacity of the beam. It was shown how instability played an important role in defining the failure modes, specifically in the end-two-flange (ETF) loading configuration, which was prone to web buckling phenomenon.

Chen and Wang (2015a), Chen and Wang (2015b) studied the web crippling behaviour of GFRP pultruded I and hollow square sections by conducting both experimental and numerical methods under four loading configurations, i.e. IB, ITF, EB and ETF, and with three different bearing lengths - $50 \mathrm{~mm}$, $100 \mathrm{~mm}$ and $150 \mathrm{~mm}$. The study results indicated that the difference in bearing length did not have much effect on the load-carrying capacity. Furthermore, the first notable failure mode in all specimens occur at the web-flange junction as $45^{\circ}$ diagonal cracks followed by the crushing of the top flange. In addition, the IB and ITF loading configurations provide higher failure load and exhibit a higher elastic limit than the EB and ETF configurations. In the analytical study, the pultruded GFRP sections were modelled as anisotropic and steel bearing plates as linear elastic materials. A standard rigid contact pair was established using a friction coefficient of 0.4 , and the whole model was meshed using Solid eight-node element to reduce integration time. The numerical results were in close agreement with the experimental outputs. Comprehensive experimental research can be found in the literature on web crippling strength of steel thin-walled sections, and generally, four loading configurations are recommended to perform the experimental tests. These consist of interior bearing with a solid base, IB, interior-two-flange, ITF, end bearing with a solid base, EB and end-two-flange, ETF (Chen and Wang, 2015b). This paper focuses on studying the bearing capacity and failure modes of pultruded GFRP I section incorporating different section profiles and loading configurations.

\section{Methodology}

In this section, the specimen preparation, along with the test setup, is discussed. Material properties are presented.

\subsection{Materials}

Table 1 presents the minimum material mechanical properties in accordance with BS EN 137063:2002. In the absence of detailed material characterisation, the values in Table 1 have been assumed for the profiles in this study. The profiles were supplied courtesy of Engineered Composites Ltd, UK.

Table 1. Pultruded FRP Material Properties (BS EN 13706-3-2002)

\begin{tabular}{llll}
\hline Property & Unit & Test Method & $\begin{array}{c}\text { Minimum } \\
\text { Properties }\end{array}$ \\
\cline { 3 - 4 } & & & E23 Grade \\
\hline Full Section Test & & Annex D, EN 13706-2:2002 & 23 \\
Tension modulus-axial & $\mathrm{GPa}$ & EN ISO 527-4 & 23 \\
Tension modulus-transverse & $\mathrm{GPa}$ & EN ISO 527-4 & 7 \\
Tension strength-axial & $\mathrm{MPa}$ & EN ISO 527-4 & 240 \\
Tension strength-axial & $\mathrm{MPa}$ & EN ISO 527-4 & 50 \\
Pin-bearing strength-axial & $\mathrm{MPa}$ & Annex E, EN 13706-2:2002 & 150 \\
Pin-bearing strength-transverse & $\mathrm{MPa}$ & Annex E, EN 13706-2:2002 & 70 \\
Flexural strength - axial & $\mathrm{MPa}$ & EN ISO 14125 & 240 \\
Flexural strength - transverse & $\mathrm{MPa}$ & EN ISO 14125 & 100 \\
Interlaminar shear strength-axial & $\mathrm{MPa}$ & EN ISO 14130 & 25 \\
\hline
\end{tabular}




\subsection{Specimen preparation}

A series of twenty-eight characterisation tests were conducted to investigate the behaviour of GFRP I profiles $-152 \times 76 \times 6.4 \mathrm{~mm}$, each $300 \mathrm{~mm}$ long. The profile was E23 grade according to BS EN 13706-3:2002. Circular and rectangular openings were formed on the I sections at the centre. Fig. 2 presents the specimen profiles and dimensional parameters and setting out of the openings. Control specimens are without openings. All specimens were fabricated from existing stock which were approximately $1350 \mathrm{~mm}$ in length. The openings were fabricated locally by Aquajet Ltd, Coventry. The fabrication uses state of the art pressurised water jet technique, as pictured in Fig. 1.

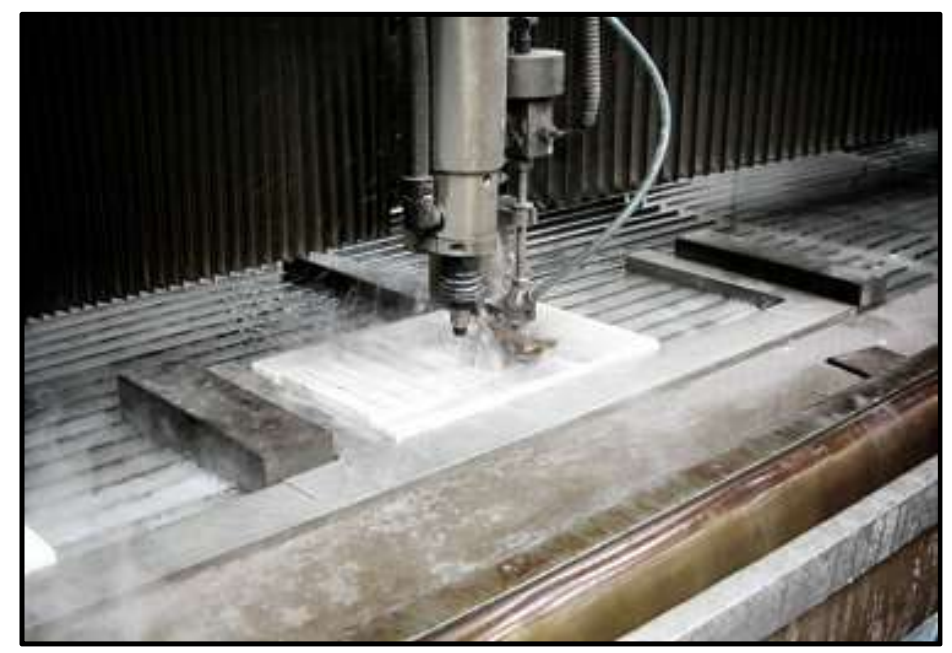

Fig. 1. Water cutting technique used to cut out the openings.

\subsection{Experimental programme}

Figs. 3 - 6 present different loading and support configurations. The loading configurations consist of an interior bearing with the solid base noted as IB; an interior-two-flange, noted as ITF; and end bearing with the solid base, noted as EB and an end-two-flange configuration, noted as ETF. Fig. 7a outlines a typical test arrangement. Schematically, the test arrangement is presented in Fig. $7 \mathrm{~b}$. The testing setup consists of a structural assembly where the specimen is placed according to specified loading configuration; mechanical clamps were used to hold the specimen firmly and to minimise lateral displacement introduced by the load application. A steel plate $78 \times 78 \mathrm{~mm}$ plan dimensions and $25 \mathrm{~mm}$ thick was used, providing a bearing contact width of $78 \mathrm{~mm}$ between the I-profile and the plate. Three linear variable differential transducers, referred herein as LVDTs, was used to measure the displacement. Two of the LVDTs were located on each side of the top flange at the point of load application to measure the vertical displacement, referred herein as $\mathrm{LVDT}_{1}$ and $\mathrm{LVDT}_{2}$. A third displacement transducer, $\mathrm{LVDT}_{3}$, was used to measure the lateral displacement at the top flange-web junction at the location of load application. A $100 \mathrm{kN}$ load cell was used to apply the load using a manually operated hydraulic jack. All specimens were labelled according to specified loading configuration and opening shapes. The data was recorded via a data logger. The characterisation tests may be summarised as; twelve control
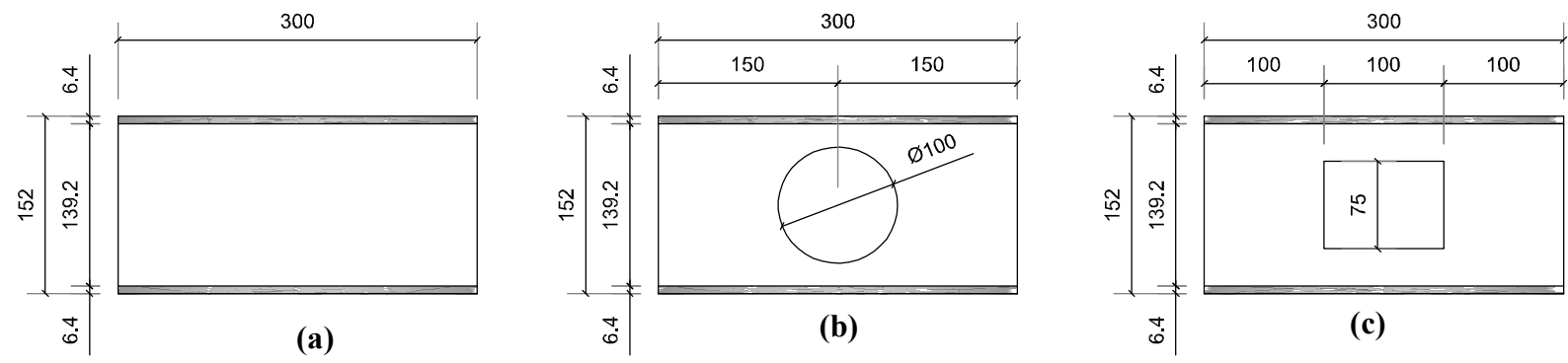

Fig. 2. GFRP I specimen - (a) control profile (b) profile with circular opening, (c) profile with rectangular opening 


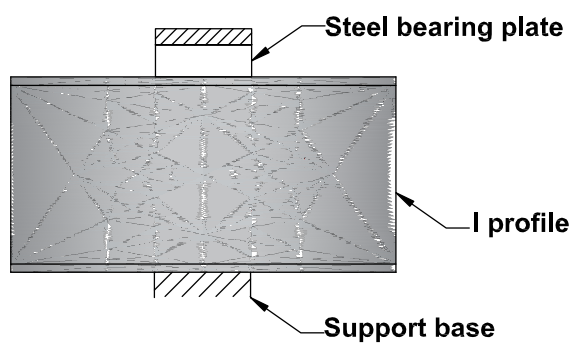

Fig. 3. Interior Two Flange (ITF), Co (1)

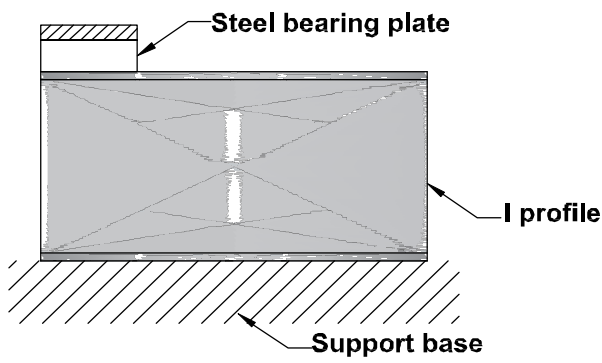

Fig. 5. End Bearing with solid ground (EB), Co (3)

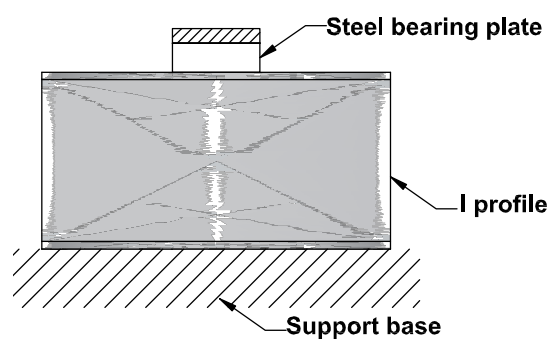

Fig. 4. Interior Bearing with solid base (IB), Co (2)

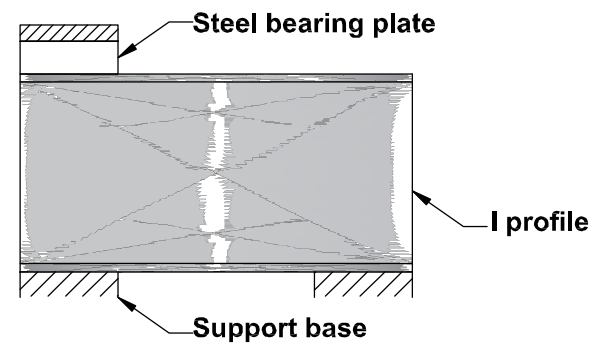

Fig. 6. End Two Flange (ETF). Co (4)

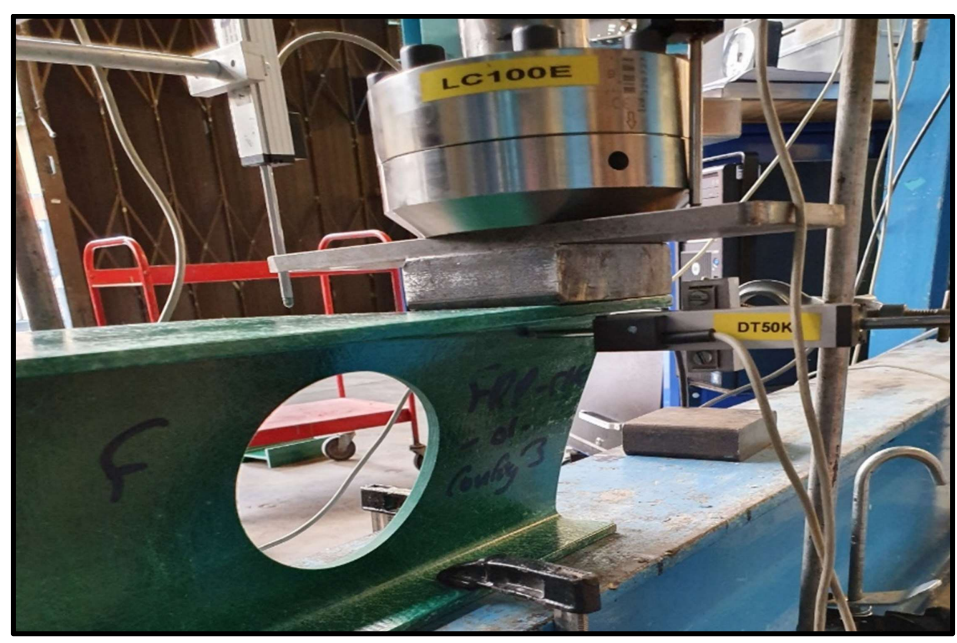

(a) specimens with no opening; seven stub beam specimens with $100 \mathrm{~mm}$ diameter circular opening located at the centre; and seven stub beam specimens with rectangular openings, $100 \mathrm{~mm}$ wide $\times 75 \mathrm{~mm}$ deep.

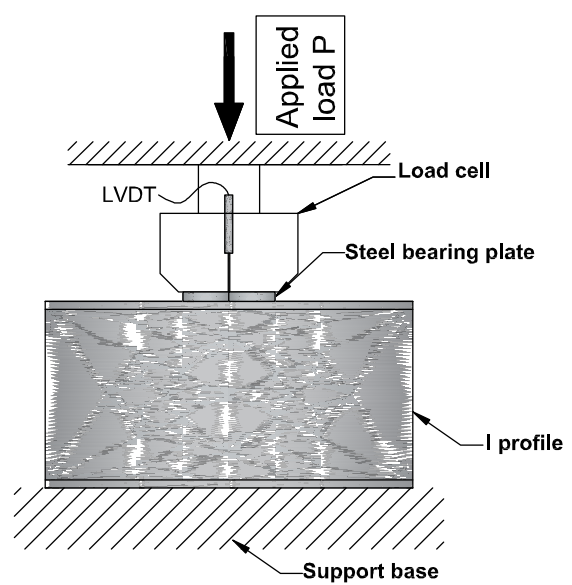

(b)

\section{Results and discussion}

Fig. 7. (a) Experimental test setup, (b) Schematic setup.

All the data obtained from the experimental test were analysed and discussed. The strength of the $\mathrm{CHC}$ and RHC specimens were compared with those of the control specimens to determine the impact of different opening shapes on the load-carrying capacity of pultruded GFRP I profiles. All modes of failure are evaluated.

\subsection{Failure mechanisms of the I profiles}

The most common failure modes observed were web-flange junction mode of failure and diagonal shear cracks forming around the opening propagating towards the web-flange junction.

\subsection{Failure mechanisms of the control specimens}

Throughout different loading configurations, the most dominant mode of failure for the control beams was web-flange junction failure. With loading configuration 1 and 2 (ITF and IB) the failure mode was similar; cracks started to form at the point of load application web-flange junction. Furthermore, in (Co 
2) these cracks propagated towards the edges while in (Co 1) the cracks remained in a concentrated position in the middle. Moreover (Co 3 and $\mathrm{Co} 4)$ exhibited similar failure modes, most of the specimen failure started by buckling of the web at the point of loading followed by cracks forming at the top and bottom edge of the web-flange junction. Similarly, the crack in (Co 3) propagated towards the middle while in (Co 4) the crack remained at a limited distance from the edge. Furthermore, delamination of the fibres can be seen at the web-flange junction.

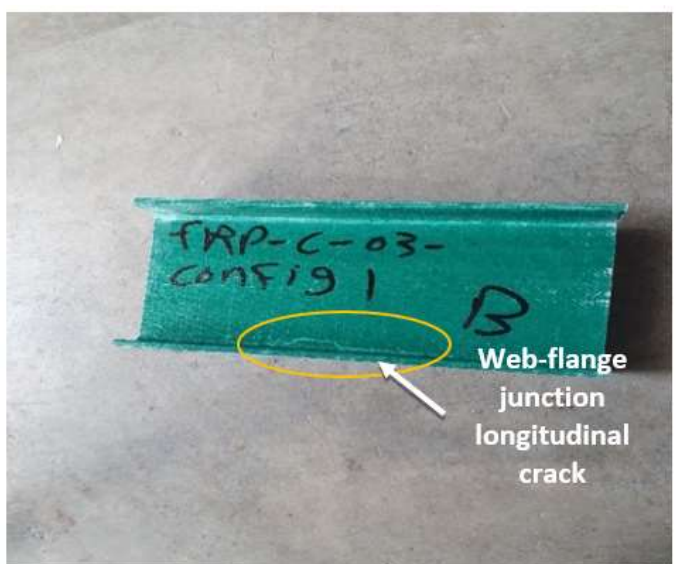

Fig. 8. Failure mode FRP-C-Co 1.

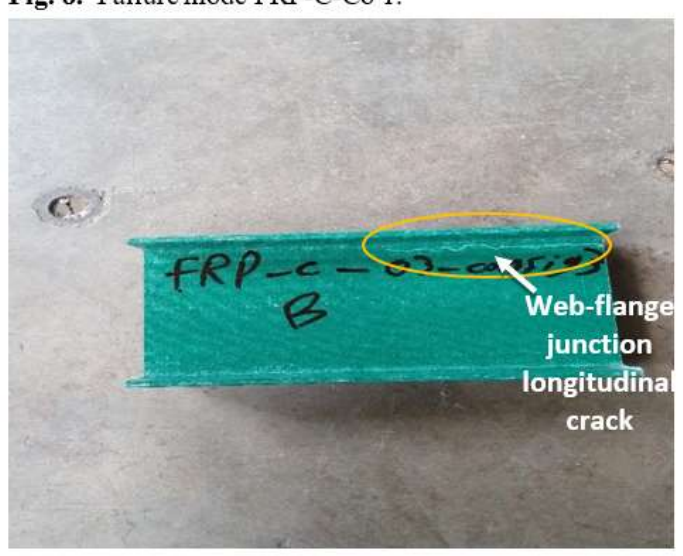

Fig. 10. Failure mode FRP-C-Co 3.
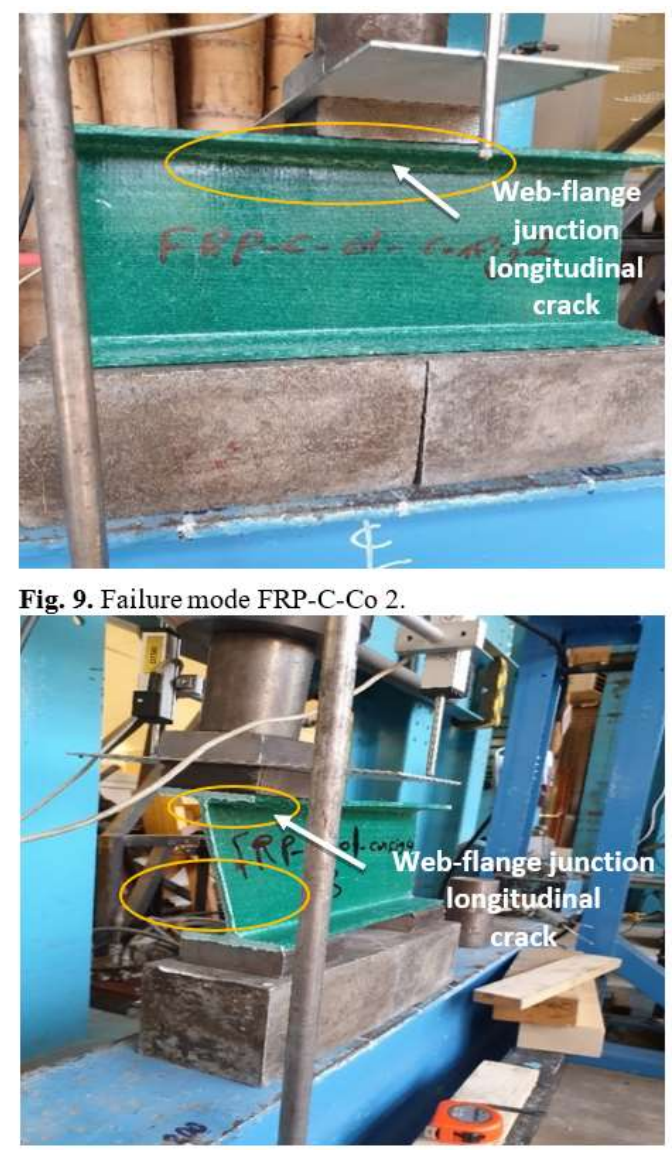

Fig. 11. Failure mode FRP-C-Co 4.

\subsection{Failure mechanisms of CHC and RHC specimens}

Specimens were identified as either having circular openings (CHC) or rectangular opening (RHC). The dominant failure mode in the circular hole centre (CHC) specimens were found to be web-flange junction failure in all loading configurations. Most of the specimens except for FRP-RHC-01-Co 3 and FRP-RHC-02-Co 3 exhibit diagonal cracks within the corners of the rectangular opening and propagating to the web. (Co 1and2) exhibit similar crack formation, the cracks form at the middle of the specimen at the web-flange junction and in (Co2) these cracks propagate to the edges of the specimen. In (Co 3and4) similar failure mode was noted with cracks forming at the edge of the beam, and in $\mathrm{Co} 3$ this crack propagates to the interior of the specimen. In Co1 and Co4, the cracks were concentrated at the reaction points and do not propagate. Fibre delamination is present within these failure modes at the web-flange junction. The dominant failure mode in the rectangular hole centre (RHC) specimens were found to be web-flange junction failure in all loading configurations. Some of the specimens, such as FRP-CHC-02-Co 1, exhibited diagonal cracks within the corners of the rectangular opening and propagate to the web. (Co 1, 2 and 4) exhibited similar crack formation, the cracks formed at the corners of the rectangle opening, and these cracks propagate to the web-flange junction of the specimen through the web. This can be seen in specimen FRP-RHC-01-Co2. In $\mathrm{Co} 3$ the failure mode started by web buckling with cracks forming at the edge of the beam, this crack propagated to the interior of the specimen. 

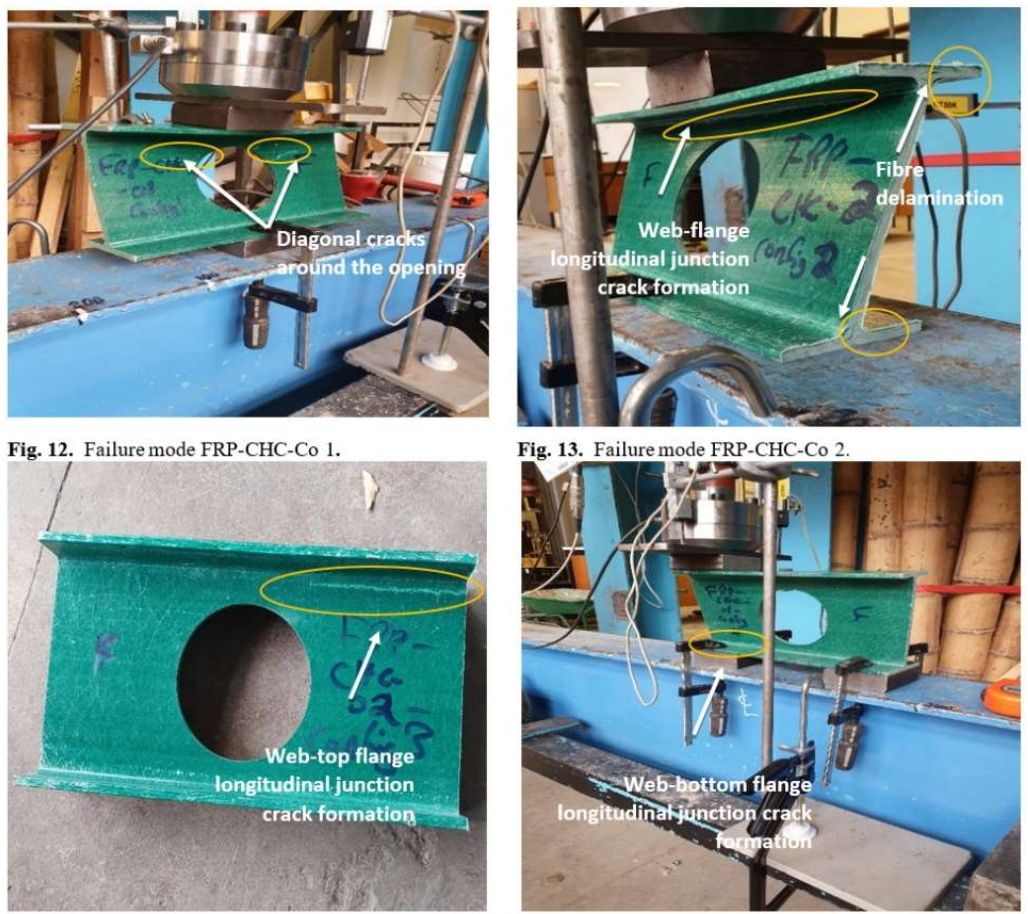

Fig. 14. Failure mode FRP-CHC-Co 3 .

Fig. 15. Failure mode FRP-CHC-Co 4.
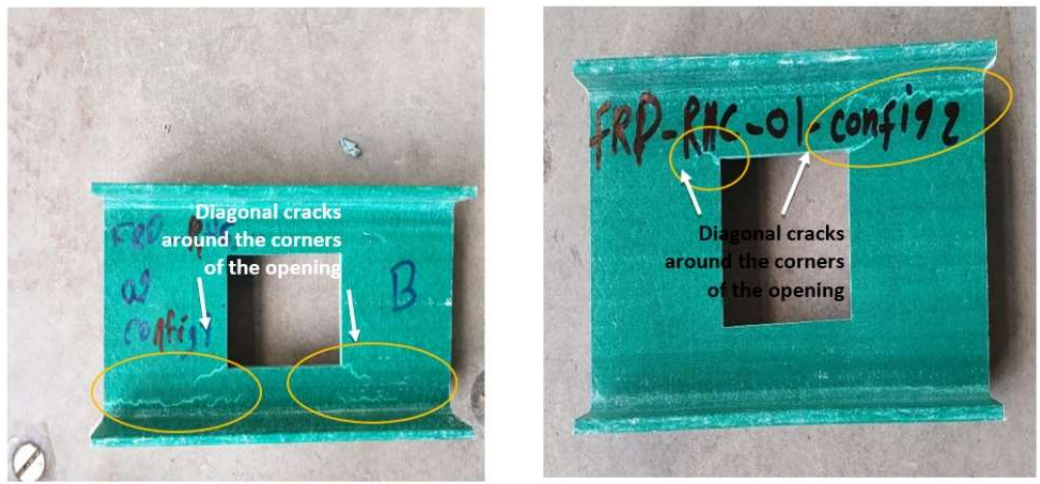

Fig. 16. Failure mode FRP-RHC-Co 1.

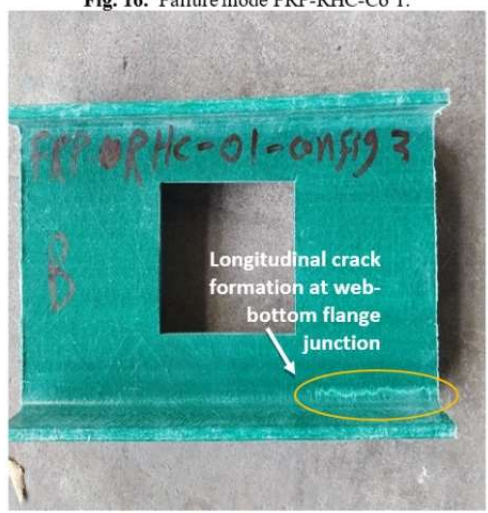

Fig. 17. Failure mode FRP-RHC-Co 2.

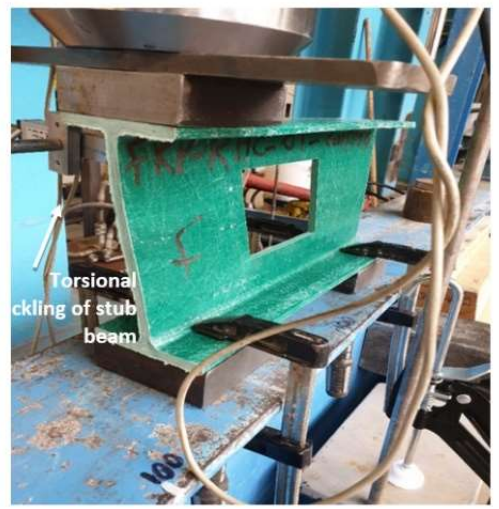

Fig. 19. Failure mode FRP-RHC-Co 4

Fig. 18. Failure mode FRP-RHC-Co 3 .

\subsection{Load versus deflection behaviour of the specimens}

Experimental results show similarities between all three specimens of the same loading configuration thus the average was estimated based on all three specimens, one exception to this was sample FRP-C-03-Co3 which 
yielded an abnormal value which is higher than the other two specimens thereby disregarding this sample when taking the average. Results indicate that loading configuration EB and ETF with an average maximum load of 10.9 $\mathrm{kN}$ and $12.9 \mathrm{kN}$, respectively are more critical for web crippling behaviour than IB and ITF loading configuration. Table 2 presents the results summary.

Table 2. FRP-C experimental result summary

\begin{tabular}{|c|c|c|c|c|c|}
\hline $\begin{array}{l}\text { Specimen ID } \\
\text { (1) }\end{array}$ & $\begin{array}{l}\text { Load at } \\
\text { failure } \\
(\mathrm{kN})(2)\end{array}$ & $\begin{array}{c}\mathrm{LVDT}_{1} \\
(\mathrm{~mm}) \\
(3)\end{array}$ & $\begin{array}{r}\mathrm{LVDT}_{2} \\
(\mathrm{~mm}) \\
(4)\end{array}$ & $\begin{array}{l}\text { Average vertical displacement } \\
(\mathrm{mm})(5)\end{array}$ & $\begin{array}{l}\text { Failure Mode } \\
\text { (6) }\end{array}$ \\
\hline FRP-C-01-Co 1 & 18.3 & 1.2 & 1.2 & \multicolumn{2}{|c|}{ Crack at top and bottom middle web-flange junction } \\
\hline FRP-C-02-Co 1 & 16.7 & -1.5 & 5 & \multicolumn{2}{|c|}{ Crack at top and bottom middle web-flange junction } \\
\hline FRP-C-03-Co 1 & 18.2 & 0.8 & 2.2 & \multicolumn{2}{|c|}{ Crack at top and bottom middle web-flange junction } \\
\hline FRP-C-01-Co 2 & 25.6 & 2.2 & 1.04 & \multicolumn{2}{|c|}{ Crack at top middle web-flange junction propagating to the edges } \\
\hline FRP-C-02-Co 2 & 20.2 & 2.9 & 0.6 & \multicolumn{2}{|c|}{ Crack at top middle web-flange junction propagating to the edges } \\
\hline FRP-C-03-Co 2 & 23.3 & 0.5 & 2.8 & \multicolumn{2}{|c|}{ Crack at top middle web-flange junction propagating to the edges } \\
\hline FRP-C-01-Co 3 & 10.7 & 3.6 & 0.4 & \multicolumn{2}{|c|}{ Crack at top and bottom edge web-flange junction } \\
\hline FRP-C-02-Co 3 & 11.2 & 2.8 & 0.5 & \multicolumn{2}{|c|}{ Crack at top and bottom edge web-flange junction } \\
\hline FRP-C-03-Co 3 & 22.7 & 2.2 & 0.2 & \multicolumn{2}{|c|}{ Crack at top edge web-flange junction } \\
\hline FRP-C-01-Co 4 & 13.45 & 4.6 & -0.6 & \multicolumn{2}{|c|}{ Crack at top and bottom edge web-flange junction } \\
\hline FRP-C-02-Co 4 & 12 & -0.1 & 3.2 & \multicolumn{2}{|c|}{ Crack at top and bottom edge web-flange junction } \\
\hline FRP-C-03-Co 4 & 13.2 & -0.3 & 4.4 & \multicolumn{2}{|c|}{ Crack at top and bottom edge web-flange junction } \\
\hline
\end{tabular}

Test results for both $\mathrm{CHC}$ and $\mathrm{RHC}$ specimens show a similarity between all two specimens of the same loading configuration; thus, the average was estimated based on these specimens. The average results are presented in Table 3 .

Table 3. FRP-CHC and RHC experimental result summary

\begin{tabular}{|c|c|c|c|c|c|c|}
\hline Specimen ID & $\begin{array}{l}\text { Load at } \\
\text { failure } \\
\text { (kN) }\end{array}$ & $\begin{array}{l}\text { LVDT }_{1} \\
(\mathrm{~mm})\end{array}$ & $\begin{array}{l}\mathbf{L V D T}_{2} \\
(\mathrm{~mm})\end{array}$ & $\begin{array}{l}\mathbf{L V D T}_{3} \\
(\mathrm{~mm})\end{array}$ & $\begin{array}{l}\text { Average vertical } \\
\text { displacement } \\
(\mathrm{mm}) \\
(6)\end{array}$ & Failure mode \\
\hline (1) & (2) & (3) & (4) & (5) & & (7) \\
\hline FRP-CHC-01-Co 1 & 13.8 & 5.9 & 0.2 & -13.1 & 3 & $\begin{array}{l}\text { Crack at top middle web-flange junction } \\
\text { propagating to the edge }\end{array}$ \\
\hline FRP-CHC-02-Co 1 & 15.4 & 3.2 & 2.1 & -13.0 & 2.6 & $\begin{array}{l}\text { Crack at bottom middle web-flange junction } \\
\text { propagating to the edge }+ \text { horizontal crack at } \\
\text { middle of circular opening. }\end{array}$ \\
\hline FRP-CHC-01-Co 2 & 17.3 & -0.2 & 3.9 & 7.7 & 1.8 & $\begin{array}{l}\text { Crack at bottom middle web-flange junction } \\
\text { propagating to the edge }\end{array}$ \\
\hline FRP-CHC-02-Co 2 & 16.3 & 3.2 & 0.7 & -12.4 & 1.9 & $\begin{array}{l}\text { Crack at top and bottom middle web-flange } \\
\text { junction propagating to the edge }\end{array}$ \\
\hline FRP-CHC-01-Co 3 & 17.1 & -1.5 & 2.9 & -3.3 & 0.7 & Crack at top edge web-flange junction \\
\hline FRP-CHC-02-Co 3 & 13.9 & -1.5 & 3.8 & 7.3 & 1.1 & Crack at top edge web-flange junction \\
\hline FRP-CHC-01-Co 4 & 14.4 & -0.9 & 3.4 & 6.8 & 1.2 & $\begin{array}{l}\text { Crack at Top and Bottom edge Web-Flange } \\
\text { junction }\end{array}$ \\
\hline FRP-RHC-01-Co 1 & 18.14 & -0.8 & 6 & 8.4 & 2.5 & $\begin{array}{l}\text { Crack at top corners of the rectangular opening } \\
\text { propagating to the edges through the web-flange } \\
\text { junction }\end{array}$ \\
\hline FRP-RHC-02-Co 1 & 17 & 4.3 & 0.4 & -8.4 & 2.3 & $\begin{array}{l}\text { Full Crack at top web-flange junction }+ \text { Crack at } \\
\text { top corners of rectangular opening }\end{array}$ \\
\hline FRP-RHC-01-Co 2 & 17.1 & 3.8 & 0.3 & -13.0 & 2.1 & $\begin{array}{l}\text { Crack at top corners of the rectangular opening } \\
\text { propagating to the edges }\end{array}$ \\
\hline FRP-RHC-02-Co 2 & 18.8 & 0.001 & 4.6 & 5.6 & 2.3 & $\begin{array}{l}\text { Full Crack at bottom web-flange junction }+ \\
\text { Crack at top corners of rectangular opening }\end{array}$ \\
\hline FRP-RHC-01-Co 3 & 13.8 & 3.6 & -0.9 & -8.9 & 1.3 & Crack at top and bottom web-flange junction \\
\hline FRP-RHC-02-Co 3 & 15.9 & 2.9 & 0.5 & -9.7 & 1.7 & Crack at top and bottom web-flange junction \\
\hline FRP-RHC-01-Co 4 & 12 & 3.1 & -0.6 & -7.8 & 1.2 & Crack at left corners of rectangular opening \\
\hline
\end{tabular}


Table 4. FRP-CHC and RHC average experimental result summary

\begin{tabular}{ccc}
\hline & \multicolumn{3}{c}{ Experimental results } \\
\cline { 2 - 3 } Specimen ID & Average maximum load (kN) & Average displacement (mm) \\
\hline FRP-CHC-Co 1 & 14.6 & 2.9 \\
FRP-CHC-Co 2 & 16.8 & 1.9 \\
FRP-CHC-Co 3 & 15.5 & 1.9 \\
FRP-CHC-Co 4 & 14.5 & 1.3 \\
FRP-RHC-Co 1 & 17.6 & 2.5 \\
FRP-RHC-Co 2 & 18.0 & 2.2 \\
FRP-RHC-Co 3 & 14.9 & 1.5 \\
FRP-RHC-Co 4 & 12.1 & 1.2 \\
\hline
\end{tabular}

Table 5. Effect of CHC and RHC opening on strength capacity of control beams

\begin{tabular}{|c|c|c|}
\hline \multirow[t]{2}{*}{ Average between Specimens } & \multicolumn{2}{|c|}{ Experimental results } \\
\hline & $\begin{array}{l}\text { Average maximum load reduction } \\
\qquad(\mathrm{kN})\end{array}$ & $\begin{array}{c}\text { Average displacement reduction } \\
(\mathrm{mm})\end{array}$ \\
\hline $\mathrm{C}$ and $\mathrm{CHC}$ Co 1 & $-21 \%$ & $48 \%$ \\
\hline $\mathrm{C}$ and $\mathrm{CHC}$ Co 2 & $-37 \%$ & $12 \%$ \\
\hline $\mathrm{C}$ and $\mathrm{CHC}$ Co 3 & $29 \%$ & $-1 \%$ \\
\hline $\mathrm{C}$ and $\mathrm{CHC} \mathrm{Co} 4$ & $11 \%$ & $-49 \%$ \\
\hline $\mathrm{C}$ and RHC Co 1 & $0 \%$ & $39 \%$ \\
\hline $\mathrm{C}$ and $\mathrm{RHC}$ Co 2 & $-28 \%$ & $24 \%$ \\
\hline $\mathrm{C}$ and $\mathrm{RHC}$ Co 3 & $26 \%$ & $-23 \%$ \\
\hline $\mathrm{C}$ and $\mathrm{RHC} \mathrm{Co} 4$ & $-7 \%$ & $-52 \%$ \\
\hline
\end{tabular}

The experimental results show no significant difference between the different loading configurations since the dominant failure mode was web-flange junction failure due to lack of stiffness of the webflange junction and non-concentric load application since no restraint was provided to prevent lateraltorsional buckling. The delamination of the fibres at the junction can be observed, which results in weak points along with the specimen hence initiating the failure mode. In comparing these specimens with the control specimens, it is noted that the presence of opening leads to the following reductions in loadcarrying capacity of the specimens. In Table 5, the negative values indicate a reduction and the positive values indicate an increase.

For the $\mathrm{CHC}$ specimens under all loading configurations, the cracks started forming at the web-flange junction due to fibre delamination. In configurations IB and ITF, the cracks started forming at the top and bottom middle of the web-flange junction whereas for configurations EB and ETF the cracks started forming after an initial buckling of the web at the edge of the specimen at point of load application. It is to be noted that in loading configuration IB, ITF the cracks started propagating towards the edges, which indicate higher non-linear response and deformability of the specimen. Specimen FRP-CHC-02-Co 1 exhibits different failure mode with diagonal cracks forming at the circular opening boundary and propagating to the edges through the web-flange junction.

For most RHC specimens under various loading configurations, the cracks started forming at the Corners of the rectangular-shaped opening. In configurations IB, ITF and ETF, the cracks started forming at the corners of the rectangle where the stresses are concentrated followed by web-flange junction failure whereas for configurations EB) the cracks started forming at the web-flange junction at point of load application then some of the corners started developing minor cracks. It is to be noted that in loading configuration IB and ITF, the cracks started propagating towards the edges, which indicating higher nonlinear response and deformability of the specimen. 
Twelve control sections were tested experimentally under loading configuration ITF, IB, ETF, and EB. There were three specimens per each test batch. Figures 19-30 present load-displacement relationships of specimens for the different loading configurations. The average load capacity for the three specimens under configuration, Co 1 was $17.6 \mathrm{kN}$, with corresponding average vertical displacement of $1.5 \mathrm{~mm}$. The average maximum load for configuration, Co 2 was $23 \mathrm{kN}$, with corresponding average vertical displacement of $1.6 \mathrm{~mm}$. For configuration Co 3 , the average maximum load recorded was $11 \mathrm{kN}$, with corresponding average vertical displacement of $1.8 \mathrm{~mm}$. Also, for configuration Co 4, the average maximum load was $13 \mathrm{kN}$, with corresponding average vertical displacement of $1.8 \mathrm{~mm}$.

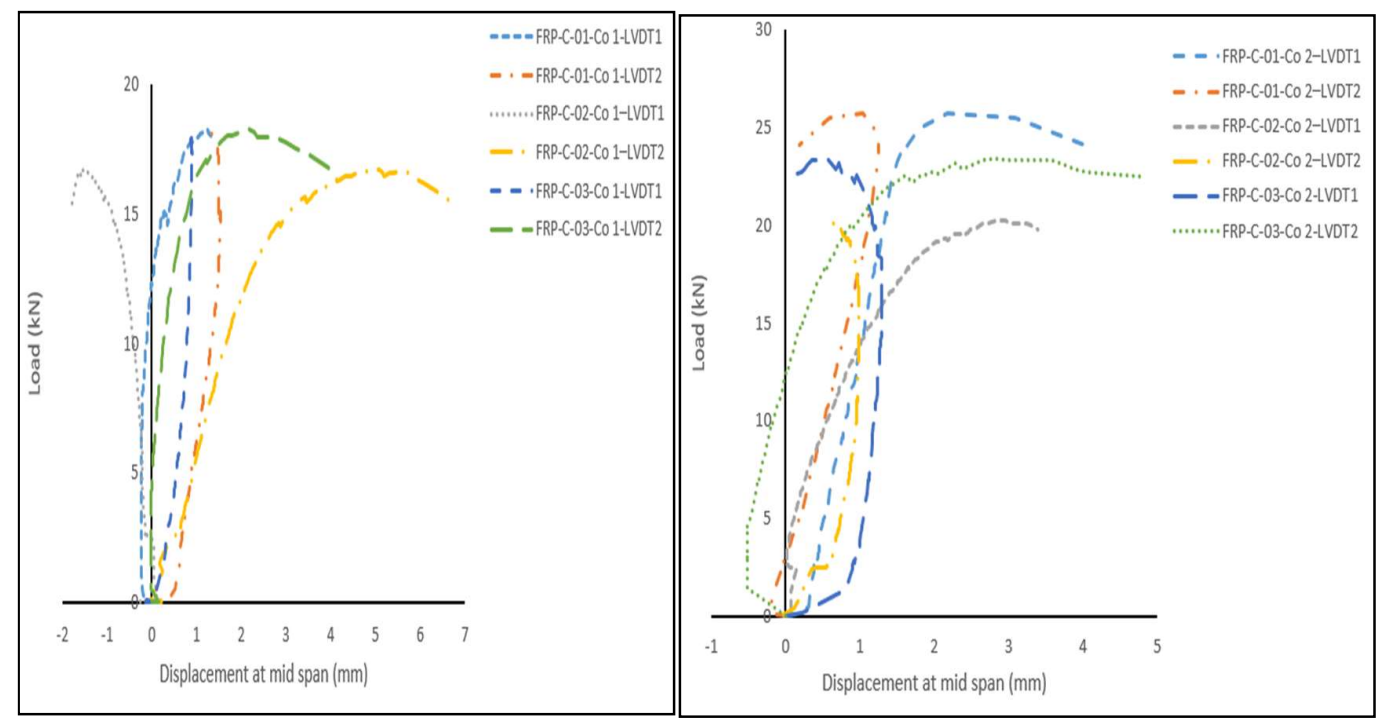

Fig. 20. Load-displacement plot - FRP-C-Co 1

Fig. 21. Load-displacement plot - FRP-C-Co 2

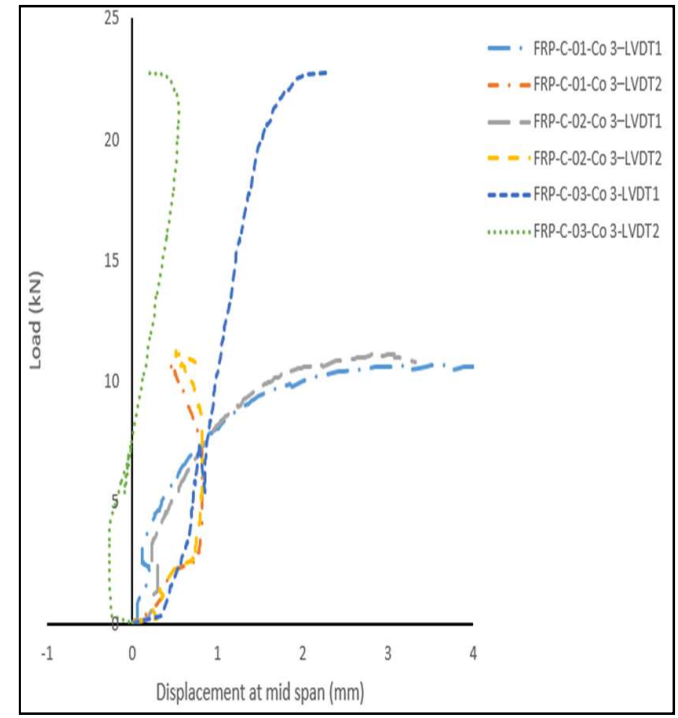

Fig. 22. Load-displacement plot - FRP-C-Co 3

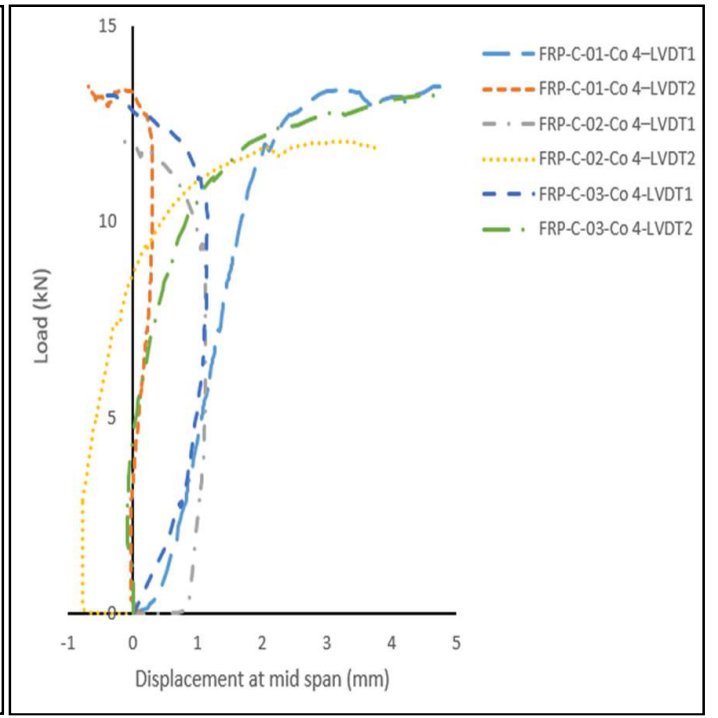

Fig. 23. Load-displacement plot - FRP-C-Co 4

Fourteen stub beam specimens with circular and rectangular perforations were tested experimentally under loading configurations ITF, IB and EB. Each batch had two specimens, except configuration ETF, which had one specimen per batch. The average maximum load for the $\mathrm{CHC}$ and RHC specimens Col was $14.6 \mathrm{kN}$ and $17.5 \mathrm{kN}$, respectively. The corresponding average vertical displacement was $2.8 \mathrm{~mm}$ 
and $2.4 \mathrm{~mm}$, respectively. The average maximum load for $\mathrm{CHC}$ and $\mathrm{RHC}$ specimens $\mathrm{Co} 2$ was $16.8 \mathrm{kN}$ and $18.0 \mathrm{kN}$, respectively, with respective corresponding average vertical displacement of $1.9 \mathrm{~mm}$ and $2.2 \mathrm{~mm}$. Similarly, the average maximum load for $\mathrm{CHC}$ and $\mathrm{RHC}$ specimens for $\mathrm{Co} 3$ was $15.4 \mathrm{kN}$ and $14.8 \mathrm{kN}$, with corresponding average vertical displacement of $1.8 \mathrm{~mm}$ and $1.5 \mathrm{~m}$, respectively. The average maximum load for $\mathrm{CHC}$ and $\mathrm{RHC}$ specimens $\mathrm{Co} 4$ was $14.4 \mathrm{kN}$ and $12.1 \mathrm{kN}$, with corresponding average vertical displacement of $1.2 \mathrm{~mm}$ for both specimens.

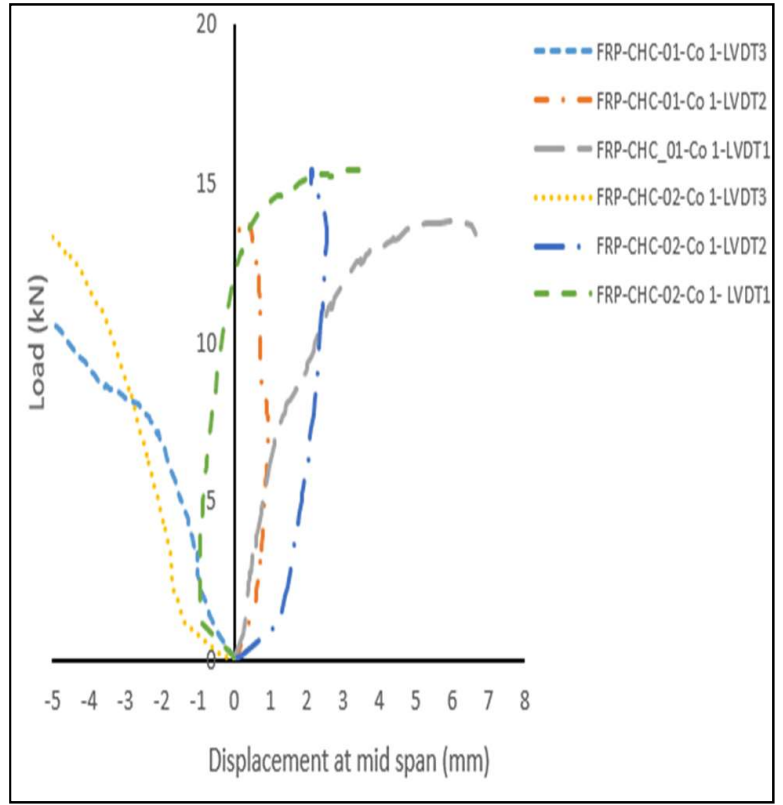

Fig. 24. Load-displacement plot - FRP-CHC-Co 1

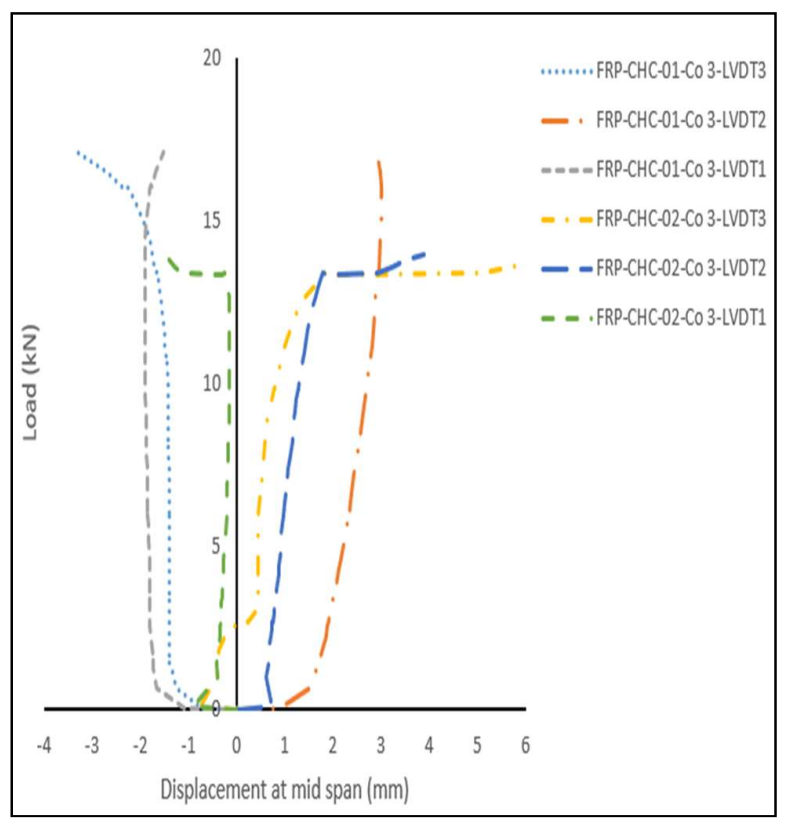

Fig. 26. Load-displacement plot, - FRP-CHC-Co 3

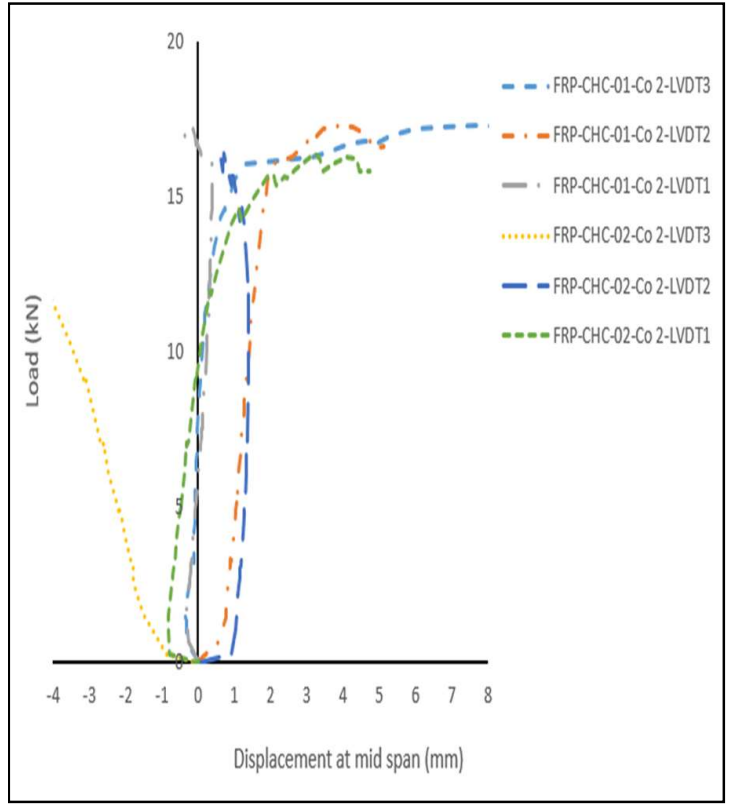

Fig. 25. Load-displacement plot - FRP-CHC-Co 2

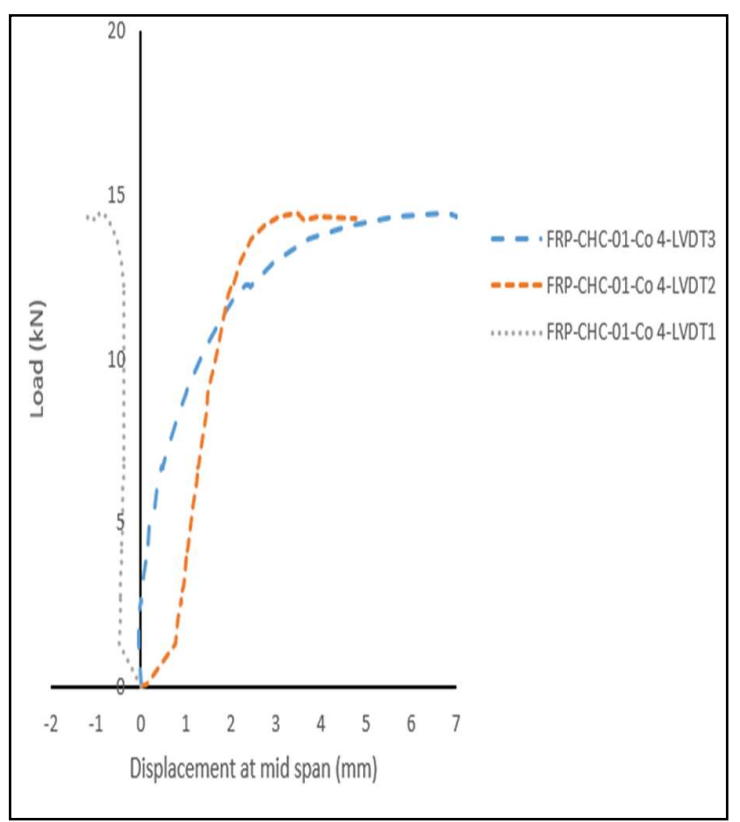

Fig. 27. Load-displacement plot - FRP-CHC-Co 4 


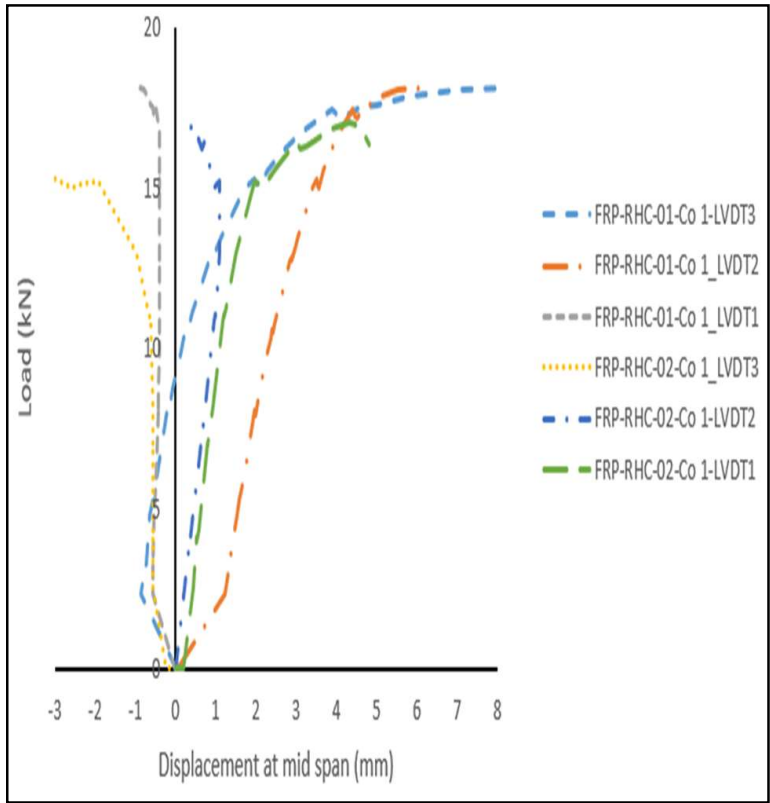

Fig. 28. Load-displacement graph FRP-RHC-Co 1.

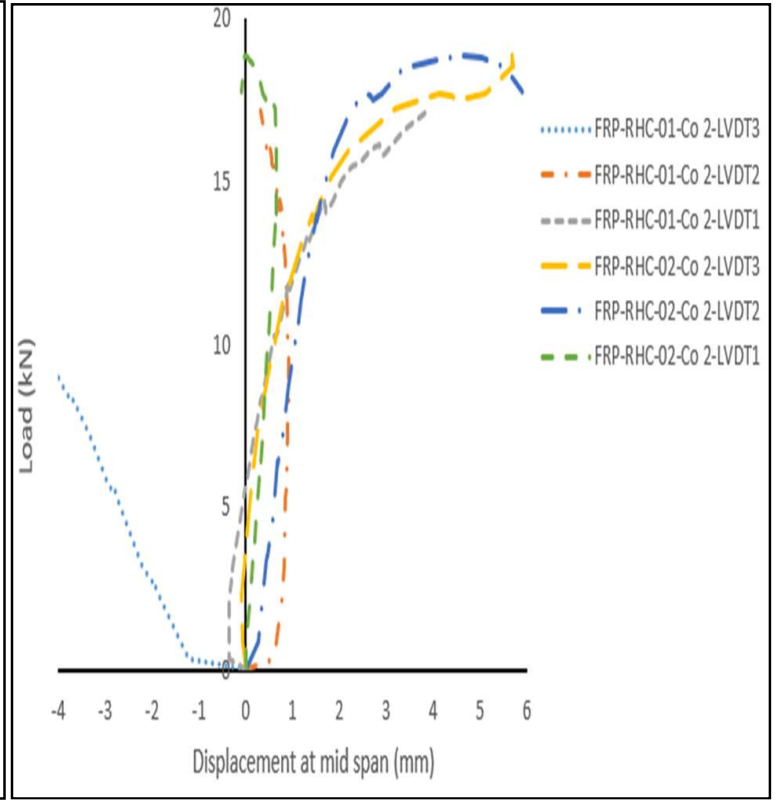

Fig. 29. Load-displacement graph FRP-RHC-Co 2.
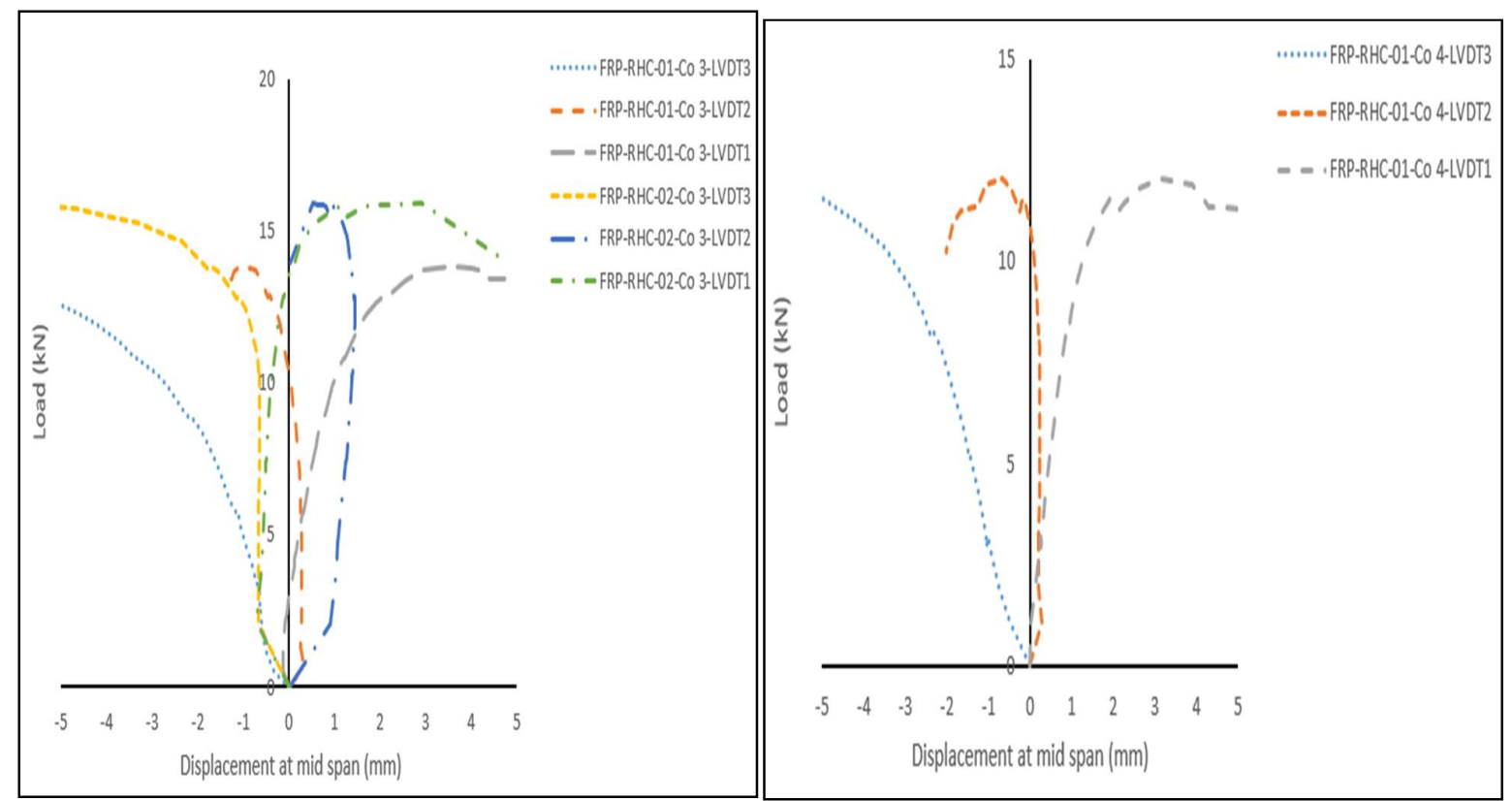

Fig. 30. Load-displacement graph FRP-RHC-Co 3.

Fig. 31. Load-displacement graph FRP-RHC-Co 4.

\section{Concluding remarks}

The experimental study reported in this paper provides a further understanding of the behaviour of GFRP pultruded I section beams with different opening shapes and different loading configuration. A total of twentyeight specimens were tested under four different loading configurations. The experiment included twelve control stub beams, seven circular opening specimen located at the middle of the specimen and seven rectangular opening specimen located at the middle of the specimen. The experimental data and research collected have supported the following concluding remarks:

1. For the control specimen tests, it is concluded that EB and ETF loading configurations are most critical and the specimens tested under IB and ITF provide more deformability and larger plasticity. The opposite is true for $\mathrm{RHC}$ and $\mathrm{CHC}$ specimens. Maximum experimental load carrying capacity and average vertical 
displacement range between $11-23 \mathrm{kN}$ and $1.5-1.8 \mathrm{~mm}$. Maximum numerical load carrying capacity and average vertical displacement range between $35.9-50.8 \mathrm{kN}$ and $3.7-5.5 \mathrm{~mm}$.

2. The presence of the opening generally reduces the strength of the beam approximately by $20 \%$ for $\mathrm{CHC}$ specimens and $25 \%$ for RHC specimens.

3. The dominant failure mode in most of the control specimens was found to be web-flange junction mode, in $\mathrm{CHC}$ and $\mathrm{RHC}$ specimens the dominant failure mode is a web-flange junction, one of the CHC specimens developed diagonal cracks near the circular opening. The RHC specimens mostly developed cracks at the corners of the rectangular opening and web-flange junction mode.

4. Comparing the control specimens with the $\mathrm{CHC}$ and $\mathrm{RHC}$ data reveals the efficiency of circular opening compared to the rectangular opening.

\section{Acknowledgement}

The authors are particularly thankful to the technicians at the School of Energy, Construction and Environment, Coventry University, for their assistance in the fabrication of the test specimens.

Conflict of Interest: The authors declare that they have no conflict of interest.

\section{References}

Bank, L., Gentry, T., \& Nadipelli, M. (1996). Local buckling of pultruded FRP beams-analysis and design. Journal of Reinforced Plastics and Composites, 15(3), 283-294.

Borowicz, D., \& Bank, L. (2011). Behaviour of pultruded fiber-reinforced polymer beams subjected to concentrated loads in the plane of the web. Journal of Composites for Construction, 15(2), 229-238.

Borowicz, D., \& Bank, L. (2013). Effect of web reinforcement on the behaviour of pultruded fibre-reinforced polymer beams subjected to concentrated loads. Construction and Building Materials, 47, 347-357.

British Standards Institution (2002) Reinforced plastic composites - Specifications for pultruded profiles - Part 3: Specific requirements. BS EN 13706-3:2002. London: British Standards Institution.

Chen, Y., \& Wang, C. (2015a). Web crippling behaviour of pultruded GFRP rectangular hollow sections. Composites Part B: Engineering, 77, 112-121.

Chen, Y., \& Wang, C. (2015b). Test on pultruded GFRP I-section under web crippling. Composites Part B: Engineering, 77, 27-37.

Durif, S., \& Bouchair, A. (2016). Analytical model to predict the resistance of cellular beams with sinusoidal openings. Journal of Constructional Steel Research, 121, 80-96.

Durif, S., Bouchaïr, A., \& Vassart, O. (2013). Experimental tests and numerical modelling of cellular beams with sinusoidal openings. Journal of Constructional Steel Research, 82, 72-87.

Erdal, F., Doğan, E., \& Saka, M. (2011). Optimum design of cellular beams using harmony search and particle swarm optimisers. Journal of Constructional Steel Research, 67(2), 237-247.

Fernandes, L., Gonilha, J., Correia, J., Silvestre, N., \& Nunes, F. (2015). Web-crippling of GFRP pultruded profiles. Part 1: Experimental study. Composite Structures, 120, 565-577.

Hai, N., Mutsuyoshi, H., Asamoto, S., \& Matsui, T. (2010). Structural behaviour of hybrid FRP composite Ibeam'. Construction and Building Materials, 24(6), 956-969.

Panedpojaman, P., Thepchatri, T., \& Limkatanyu, S. (2015). Novel simplified equations for Vierendeel design of beams with (elongated) circular openings. Journal of Constructional Steel Research, 112, 10-21.

Pachpor, P., Gupta, L., \& Deshpande, N. (2014). Analysis and design of cellular beam and its verification. IERI Procedia, 7, 120-127.

Qiao, P., Davalos, J., \& Brown, B. (2000). A systematic analysis and design approach for single-span FRP deck/stringer bridges. Composites Part B: Engineering, 31(6-7), 593-609.

Zirakian, T., \& Showkati, H. (2006). Distortional buckling of castellated beams. Journal of Constructional Steel Research, 62(9), 863-871. 
(C) 2020 by the authors; licensee Growing Science, Canada. This is an open access article distributed under the terms and conditions of the Creative Commons Attribution (CC-BY) license (http://creativecommons.org/licenses/by/4.0/). 